\title{
Annual particle flux observations over a heterogeneous urban area
}

\author{
L. Järvi ${ }^{1}$, Ü. Rannik ${ }^{1}$, I. Mammarella ${ }^{1}$, A. Sogachev ${ }^{2}$, P. P. Aalto ${ }^{1}$, P. Keronen ${ }^{1}$, E. Siivola ${ }^{1}$, M. Kulmala ${ }^{1}$, and \\ T. Vesala ${ }^{1,3}$ \\ ${ }^{1}$ Department of Physics, P.O. Box 48, 00014 University of Helsinki, Finland \\ ${ }^{2}$ Ris $\varnothing$ National Laboratory for Sustainable Energy, Technical University of Denmark, P.O. Box 49, 4000 Roskilde, Denmark \\ ${ }^{3}$ Department of Forest Ecology, P.O. Box 27, 00014 University of Helsinki, Finland
}

Received: 24 April 2009 - Published in Atmos. Chem. Phys. Discuss.: 17 June 2009

Revised: 2 October 2009 - Accepted: 2 October 2009 - Published: 20 October 2009

\begin{abstract}
Long-term eddy covariance particle number flux measurements for the diameter range $6 \mathrm{~nm}$ to $5 \mu \mathrm{m}$ were performed at the SMEAR III station over an urban area in Helsinki, Finland. The heterogeneity of the urban measurement location allowed us to study the effect of different land-use classes in different wind directions on the measured fluxes. The particle number fluxes were highest in the direction of a local road on weekdays, with a daytime median flux of $0.8 \times 10^{9} \mathrm{~m}^{-2} \mathrm{~s}^{-1}$. The particle fluxes showed a clear dependence on traffic rates and on the mixing conditions of the boundary layer. The measurement footprint was estimated by the use of both numerical and analytical models. Using the crosswind integrated form of the footprint function, we estimated the emission factor for the mixed vehicle fleet, yielding a median particle number emission factor per vehicle of $3.0 \times 10^{14} \# \mathrm{~km}^{-1}$. Particle fluxes from the vegetated area were the lowest with daytime median fluxes below $0.2 \times 10^{9} \mathrm{~m}^{-2} \mathrm{~s}^{-1}$. During weekends and nights, the particle fluxes were low from all land use sectors being in the order of $0.02-0.1 \times 10^{9} \mathrm{~m}^{-2} \mathrm{~s}^{-1}$. On an annual scale the highest fluxes were measured in winter, when emissions from stationary combustion sources are also highest. Particle number fluxes were compared with the simultaneously measured $\mathrm{CO}_{2}$ fluxes and similarity in their sources was distinguishable. For $\mathrm{CO}_{2}$, the median emission factor of vehicles was estimated to be $370 \mathrm{~g} \mathrm{~km}^{-1}$.
\end{abstract}

\section{Introduction}

Atmospheric aerosol particles are known to have adverse health effects especially in urban areas (Curtis et al., 2006; Keeler et al., 2005), where many pollution sources are lo-

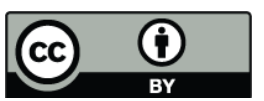

Correspondence to: L. Järvi

(leena.jarvi@helsinki.fi) cated, and where a large number of people are exposed to these pollutants. Aerosol particles also affect global climate directly by either cooling or warming the atmosphere depending on the particle composition, or indirectly acting as cloud condensation nuclei and further affecting the atmospheric radiation balance (Intergovernmental Panel on Climate Change, 2007). In urbanized areas, road traffic has been identified as the main source especially for ultra-fine particles, which can either be directly emitted or formed in secondary reactions from exhaust gases (e.g. Thomas and Morawska, 2002; Young and Keeler, 2007; Järvi et al., 2009). Besides road traffic, other combustion sources are relevant for particle emissions (e.g. Pakkanen et al., 2001; Young and Keeler, 2007), with wood burning in cold regions causing high particle emissions during winter (e.g. Glasius et al., 2006). Although many of the particle sources have been identified, there is still much uncertainty in the emission strength of different sources and their contribution to particle concentrations, especially on the scale of micrometeorological flux measurements.

In natural ecosystems, much work related to particle exchange between the surface and atmosphere has been performed, whereas in cities, the number of studies is limited (as reviewed by Pryor et al., 2008). A few studies have concentrated on modelling the particle emissions in urban areas using different methods (e.g. Palmgren et al., 1999; Kumar et al., 2008), while direct particle flux measurements have been made in a few cities during shorter campaigns (Nemitz et al., 2000, 2008; Dorsey et al., 2002; Longley et al., 2004a, b; Donateo et al., 2006; Mårtensson et al., 2006; Martin et al., 2008; Schmidt and Klemm, 2008). Particle exchange measurements provide important information on the previously mentioned emission strengths and distributions of sources, and in addition yield input parameters for air quality and climate models. Recently, Schmidt and Klemm (2008) were the first to report size-resolved particle number fluxes from an urban area (from Münster, Germany), whereas Nemitz et

Published by Copernicus Publications on behalf of the European Geosciences Union. 
al. (2008) reported the first results on the fluxes of chemical species of particulate matter (from Boulder, Colorado).

In Helsinki, Finland, continuous measurements of particle number fluxes using the eddy covariance (EC) technique were started at the SMEAR III urban measurement station in July 2007. The EC technique provides the most direct measure of the vertical exchange of particles, and the measurement system was able to detect particles ranging from $6 \mathrm{~nm}$ to $5 \mu \mathrm{m}$ in aerodynamic diameter. The main particle sources in Helsinki are identified as energy production, road traffic and wood burning accounting for 32, 28 and 29 percent of the total particle mass $\left(\mathrm{PM}_{10}\right)$ emissions, which were estimated to be 1042 tons $\mathrm{yr}^{-1}$ in 2007 (Niemi et al., 2008). The complex measurement site provides an opportunity to study the effect of different types of land use on particle exchange, while the northern measurement location enables us to analyse the fluxes in varying meteorological conditions with distinguishable seasons. The main purpose of this study is to analyse the effect of different land uses on the exchange process and the temporal behaviour of the flux, up to a seasonal time scale. The influence of traffic rate and atmospheric mixing on the particle number fluxes as well as the correlation of the particle number and carbon dioxide $\left(\mathrm{CO}_{2}\right)$ fluxes are also studied.

Emission velocity, defined by negative flux to concentration ratio, is a frequently used variable employed in the analysis and characterisation of particle exchange over urban areas (e.g. Dorsey et al., 2002). It is well known that flux and concentration have very different source weight functions called footprint functions (e.g. Schmid, 2002), the concentration footprint function giving more weight to distant sources. In addition, the aerosol particle concentration contains a significant background component, which is determined by sources other than those inducing the flux. Moreover, concentrations are more affected by atmospheric mixing and the observation height, whereas flux is more invariant with respect to the chosen observation height and turbulence conditions. To avoid such complications and to have a more general description of local particle sources and sinks, we chose to analyse only the particle fluxes instead of the emission velocities.

\section{Measurements and methods}

\subsection{The site description}

The measurements of aerosol particle number fluxes using the EC technique were carried out at the SMEAR III urban measurement station (Station for Measuring Ecosystem - Atmosphere Relationships) in Helsinki, Finland, between July 2007 and July 2008. The measurements were made on the top boom of a $31 \mathrm{~m}$ tall triangular lattice tower situated on a hill $\left(60^{\circ} 12^{\prime} \mathrm{N}, 24^{\circ} 57^{\prime} \mathrm{E}, 26 \mathrm{~m}\right.$ above sea level) around $5 \mathrm{~km}$ north-east from Helsinki city centre. The measurement loca-

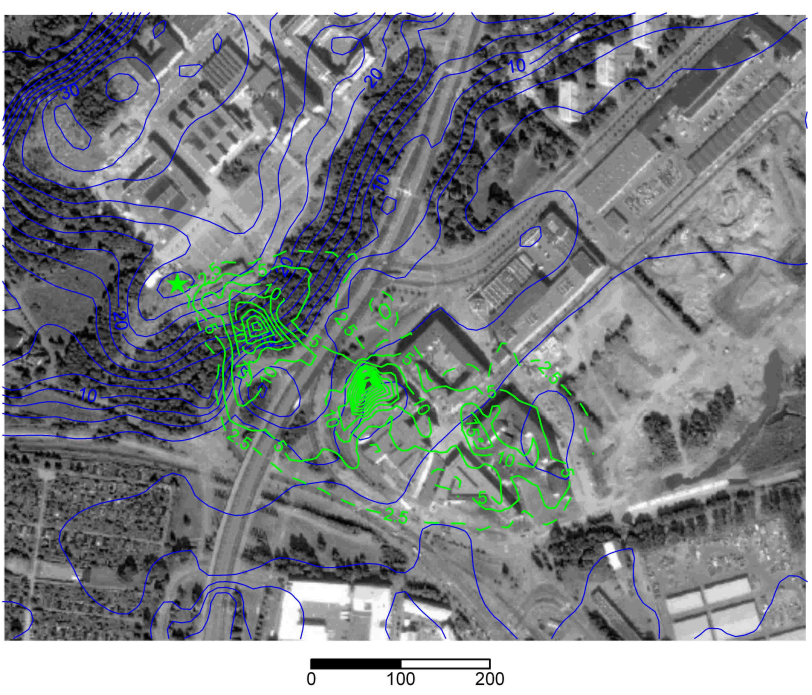

Fig. 1. Aerial photograph of the measurement location. Topography of the measurement site (relative to sea level) is denoted by blue contours. The green contours show the flux footprint function (scale $10^{-6}$, the unit of flux footprint is $\mathrm{m}^{-2}$ ) when the wind direction is perpendicular to the road $\left(117^{\circ}\right)$, geostrophic wind speed is $10 \mathrm{~m} \mathrm{~s}^{-1}$ and the boundary layer is neutrally stratified. The location of the measurement tower is marked by a green star, and its distance to the edge of the road is around $150 \mathrm{~m}$.

tion was heterogeneous, consisting of buildings, paved areas and vegetation (Fig. 1), and was divided into three land use sectors according to the typical land use in the area. The urban sector, which is mainly covered with buildings (mean height of $20 \mathrm{~m}$ ), roads and parking lots, is located in the range $320-40^{\circ}$. The road sector is in direction $40-180^{\circ}$, and one of the main roads leading to Helsinki city centre with a traffic rate of 47000 vehicles per workday (Lilleberg and Hellman, 2009) passes this sector at a distance of $150 \mathrm{~m}$ from the tower. The vegetation sector in direction $180-320^{\circ}$ is mainly covered with vegetation at both the University Botanical garden and an allotment garden. A more detailed description of the measurement site can be found in Vesala et al. (2008) and Järvi et al. (2009).

\subsection{Measurements}

The EC measurement setup consisted of a Metek ultrasonic anemometer (USA-1, Metek GmbH, Germany) to measure all three wind velocity components and sonic temperature, and a water-based condensation particle counter (WCPC, TSI-3781, TSI Incorporated, USA) to measure the aerosol particle number concentration. The 50\% cut-off size of the WCPC is $6 \mathrm{~nm}$, but it is slightly dependent on the particle composition as reported by Hering et al. (2005). Moreover, particle losses occur in the sampling line mainly due to Brownian diffusion and impaction mechanisms prevailing at small and large particle sizes, respectively. However, the 


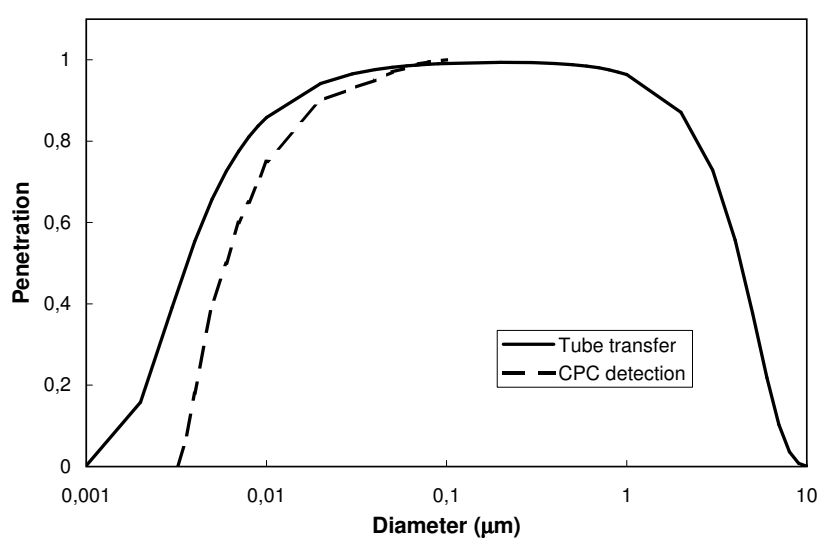

Fig. 2. Transfer efficiency of the EC system as a function of particle size. In penetration calculations (according to Baron and Willeke; 2001), the tube was assumed to consist of 10 different segments including bends. Particle density was assumed to be $1.5 \mathrm{~g} \mathrm{~cm}^{-3}$.

measurements at small particle sizes were limited by the ability of the WCPC to detect small particles and not by losses caused by the sampling line as can be seen from the particle size transfer function of the EC system shown in Fig. 2.

$\mathrm{CO}_{2}$ mixing ratios used to calculate $\mathrm{CO}_{2}$ fluxes were measured with a closed-path infrared gas analyser (LI-7000, LICOR Biosciences, USA). Both the aerosol particle number and $\mathrm{CO}_{2}$ analysers used the same air inlet situated $13 \mathrm{~cm}$ below the anemometer. The inlet was covered with a $6 \mathrm{~mm}$ diameter filter (mesh $0.1 \mathrm{~mm}$ ) and rain cover. The main tube connected to the $\mathrm{CO}_{2}$ analyser was a $40 \mathrm{~m}$ long steel tube with an inner diameter of $8 \mathrm{~mm}$. The side flow to the WCPC was drawn through a $0.1 \mathrm{~m}$ long tube from the main tube at a distance of $3.6 \mathrm{~m}$ from the inlet. The airflow in the main tube was $161 \mathrm{~min}^{-1}$ and it was heated with a power of $4 \mathrm{~W} \mathrm{~m}^{-1}$ to avoid water condensation on the walls. Inlet time lags and fluxes of aerosol particles and $\mathrm{CO}_{2}$ were determined with a maximum covariance technique (e.g. McMillen, 1988). The EC measurements were recorded at a rate of $10 \mathrm{~Hz}$. Data were recorded and will be presented in Eastern European Time (EET) without summer time correction.

The measurement period from July 2007 to July 2008 was divided into three seasons: summer, fall/winter and spring. Winter was not separated from fall since no thermal winter (daily average temperatures below $0^{\circ} \mathrm{C}$ over 5 days) was observed during the measurement period. The summer period covered July-August 2007 and June-July 2008, the fall/winter period September 2007-March 2008 and the spring period April-May 2008.

\subsection{Traffic monitoring}

Traffic rates in the Helsinki area are monitored by the Helsinki City Planning Department. The nearest on-line traffic monitoring point is on the Itäväylä road about $2.5 \mathrm{~km}$
Southeast of the measurement station. The traffic patterns on the Itäväylä road and the road next to the measurement station are similar, except traffic rates are $25 \%$ higher on the Itäväylä road (Lilleberg and Hellman, 2009). This difference was taken into account when analysing the traffic data. Traffic data were logged every hour except during rush hours, when it was logged four times per hour. Due to limited traffic data coverage, data analysis including traffic counts covered only the period from July 2007 to May 2008.

\subsection{Data processing}

With the EC technique, turbulent flux $F_{s}$ is calculated as a covariance between vertical wind speed $w$ and scalar $s$ according to the equation

$F_{S}=\overline{w^{\prime} s^{\prime}}$.

In our case, $s$ was either the aerosol particle number concentration or the mixing ratio of $\mathrm{CO}_{2}$. Before the flux calculation, data were linearly de-trended and a 2-dimensional coordinate rotation was applied. To improve the quality of the flux data, observation periods with clear spikes in particle concentration and $\mathrm{CO}_{2}$ mixing ratio records as detected by visual inspection were excluded. A stationary test according to Foken and Wichura (1996) was performed on both the particle and $\mathrm{CO}_{2}$ flux data. The measurement period used to calculate each flux value was divided into 5-min intervals and if the difference between the flux value and the mean covariance of the sub-intervals was larger than $60 \%$ the flux value was omitted. Even after the stationary test, uncertainties caused by the effect of the hill and the heterogeneous emission area are likely to remain. However, various tests to check the suitability of the EC technique have been found to be approximately valid at the measurement site (Vesala et al., 2008). Analysed data was also selected according to the condition of friction velocity being greater than $0.1 \mathrm{~m} \mathrm{~s}^{-1}$ to avoid low turbulence conditions.

Co-spectral corrections were applied to the particle and $\mathrm{CO}_{2}$ fluxes, and the attenuation factors were calculated numerically by integrating

$$
\frac{F_{s}}{F}=\frac{\int_{0}^{\infty} T F_{\mathrm{High}}(f) T F_{\mathrm{Low}}(f) C_{w s}(f) d f}{\int_{0}^{\infty} C_{w s}(f) d f},
$$

where $F_{s}$ and $F$ are the measured and un-attenuated fluxes, respectively, $f$ is the natural frequency, $T F_{\text {High }}(f)$ and $T F_{\text {Low }}(f)$ are the transfer functions in the high and low frequency regions respectively, and $C_{w s}(f)$ is the co-spectral density describing the frequency behaviour of the turbulent flux (Moore, 1986; Horst, 1997). On the grounds of scalar similarity, the co-spectral models of Kaimal et al. (1972) for sensible heat were used as $C_{w s}(f)$, and the normalized frequency $n_{m}$ at which the frequency weighted co-spectrum 


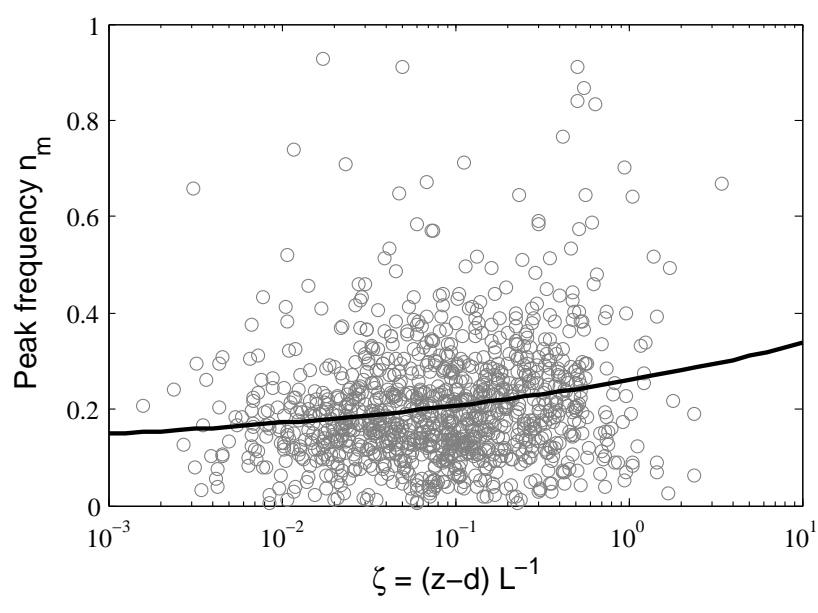

Fig. 3. The normalized peak frequency $n_{m}$ of the co-spectra of sensible heat flux as a function of atmospheric stability $\zeta$ for stable stratification in April-August 2007. The circles show the half hour data points and the black solid line is the fit corresponding to Eq. (3).

of sensible heat flux attains its maximum value was determined experimentally as a function of atmospheric stability $\zeta=\frac{z-d}{L}$, where $L$ is the Obukhov length, $z$ is the measurement height and $d$ is the displacement height (Horst, 1997; Rannik et al., 2004). $d$ was defined separately for each land use sector $(13,8$ and $6 \mathrm{~m}$ for urban, road and vegetation, respectively) as two-third the mean canopy height (Grimmond and Oke, 1999). In unstable cases, $n_{m}$ was found to be constant with a value of $0.1 \pm 0.04(\mathrm{SD})$, and in stable cases a least-square fit was made yielding Eq. (3) (plotted in Fig. 3).

$n_{m}=0.1\left(1+1.6 \zeta^{0.17}\right)$.

For the low frequency loss, $T F_{\text {Low }}(f)$ associated with the linear de-trending was used (Rannik and Vesala, 1999), while for $T F_{\text {High }}(f)$ the following co-spectral transfer function was employed

$T F_{\text {High }}(f)=\frac{1}{1+\left(2 \pi \tau_{c} f\right)^{2}}$,

where the first order response time $\tau_{c}$ was determined experimentally from the ratio of normalized co-spectral density of respective scalar and sensible heat (Rannik et al., 2004; Mammarella et al., 2009). The experimental transfer function for aerosol particle number fluxes was calculated from 270 half hourly data runs measured in March-June 2008 yielding a value of $\tau_{c}=0.5 \mathrm{~s}$.

For aerosol particle number flux, the median correction factor $F_{S} / F$ was found to be 0.9 , and the 5 and 95 percentiles were 0.85 and 0.93 , respectively.

\subsection{Footprint analysis}

Over complex topography and heterogeneous terrain, the only possible way to estimate the influence of surface sources on the measured flux is through the use of numerical calculations. The footprint simulations were performed using the numerical atmospheric boundary-layer model SCADIS (Sogachev and Lloyd, 2004; Sogachev et al., 2004; Sogachev and Panferov, 2006). The model is based on a one-anda-half-order turbulence closure applying an $E-\omega$ scheme, where $E$ is the turbulent kinetic energy and $\omega$ is the specific dissipation of $E$ (Sogachev et al., 2002; Sogachev, 2009). The model does not take the heterogeneity of urban heat fluxes into account. In simulations, land use was classified into nine different types including roads, parking areas, soil, and trees with two different height classes, and buildings with four different height classes. Buildings were considered to be impenetrable. The footprint calculation was made for the road sector with the surface wind from a direction of $117^{\circ}$, representing the direction perpendicular to the road, and a geostrophic wind speed of $10 \mathrm{~m} \mathrm{~s}^{-1}$. Neutral stratification of the atmosphere was assumed. The cell size used in the simulation was $20 \times 20 \mathrm{~m}^{2}$.

\section{Results}

In urban conditions, particle fluxes are expected to follow several drivers. The fluxes depend on wind direction due to the different surface types, while seasonal and diurnal variation is also likely to exist in the measured fluxes. In the following, these dependencies are studied in more detail.

\subsection{Particle number flux dependence on wind direction}

The highest particle number fluxes were observed when the wind direction was between east and south, the direction corresponding to the road sector (Fig. 4). In winter, the largest particle fluxes were measured from the south, in spring in the southeast, and in summer the fluxes were more evenly distributed between eastern and southern directions. In winter and spring, relatively high particle fluxes were also observed in the north, where a parking lot close to the measurement point is located. Automotive emissions from the parking lot could also explain the seasonality of this local directional maximum, since activity at the parking lot is lower in summer than in other seasons due to the summer vacations. A residential area with single family homes is also located to the north, where wood burning for heating could contribute to the observed dependence during the colder months.

Differences between the seasons were also observed in other directions. In winter, the fluxes in the south and in the sector $60-90^{\circ}$ were relatively high compared to spring and summer. These directions correspond to the location of the road. We note that the seasonal influence of atmospheric stability on flux footprints is likely to affect the observed seasonal patterns. 
Table 1. Median aerosol particle number fluxes (in $10^{6} \mathrm{~m}^{-2} \mathrm{~s}^{-1}$ ) in different seasons, land use sectors and times of day. The respective quartile deviations are also listed.

\begin{tabular}{lllllll}
\hline & \multicolumn{3}{c}{ Spring/Summer } & & \multicolumn{2}{c}{ Winter/Fall } \\
\hline & Urb & Road & Veg & Urb & Road & Veg \\
\hline Weekday daytime (10:00-15:00) & $180 \pm 149$ & $663 \pm 271$ & $119 \pm 79$ & $321 \pm 277$ & $837 \pm 348$ & $232 \pm 132$ \\
Weekend daytime (10:00-15:00) & $55 \pm 43$ & $309 \pm 127$ & $44 \pm 26$ & $91 \pm 57$ & $511 \pm 224$ & $85 \pm 46$ \\
+ Weekend night-time (23:00-04:00) & $19 \pm 14$ & $39 \pm 26$ & $16 \pm 9$ & $40 \pm 20$ & $109 \pm 62$ & $35 \pm 19$ \\
\hline
\end{tabular}
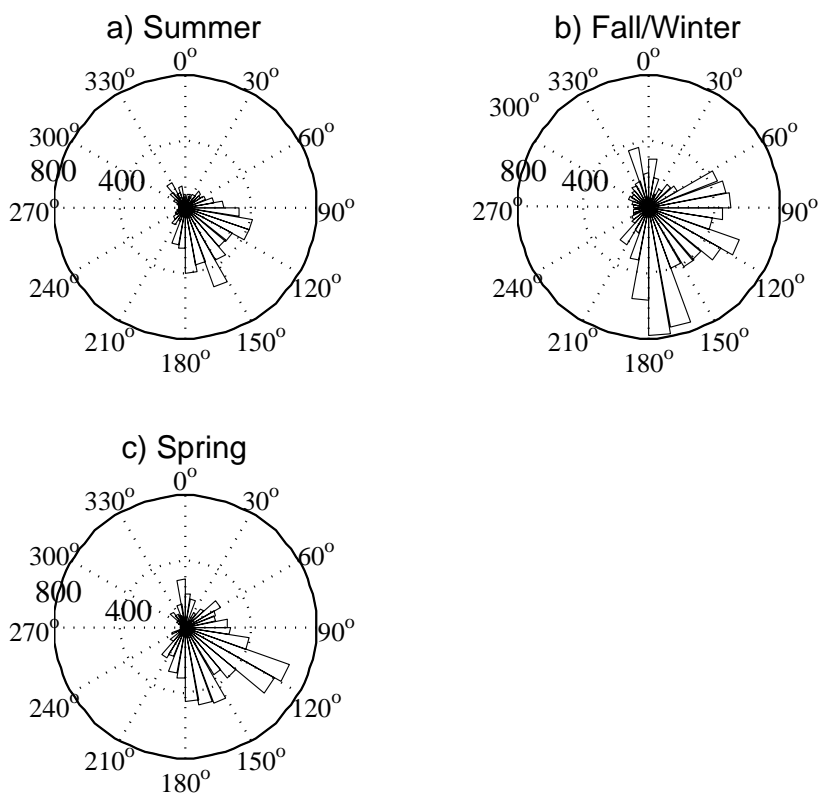

Fig. 4. The wind direction dependence of aerosol particle number fluxes $\left(F_{p}\right)$ for: (a) summer, (b) fall/winter and (c) spring. Values were calculated for $10^{\circ}$ wind sectors as medians from the 30 -min average fluxes. The units are $10^{6} \mathrm{~m}^{-2} \mathrm{~s}^{-1}$.

\subsection{Temporal variation of particle number fluxes}

As particle emissions in urban areas are mainly driven by traffic and household activity, particle fluxes are expected to show diurnal variation with differences between weekdays and weekends. The diurnal variation should also be affected by the atmospheric mixing conditions, with source-sink relationships between the areas of emission and the measurement point affected by atmospheric stability. Fig. 5 shows the diurnal variation of particle number fluxes separated into the three distinct surface types. The fluxes were systematically higher in the road sector, reaching $10^{9} \mathrm{~m}^{-2} \mathrm{~s}^{-1}$, and lower in the vegetation sector, where the fluxes remain below $300 \times 10^{6} \mathrm{~m}^{-2} \mathrm{~s}^{-1}$. Seasonal differences in the diurnal patterns were not distinguishable except in fall/winter, when the particle fluxes in the road direction were higher than in

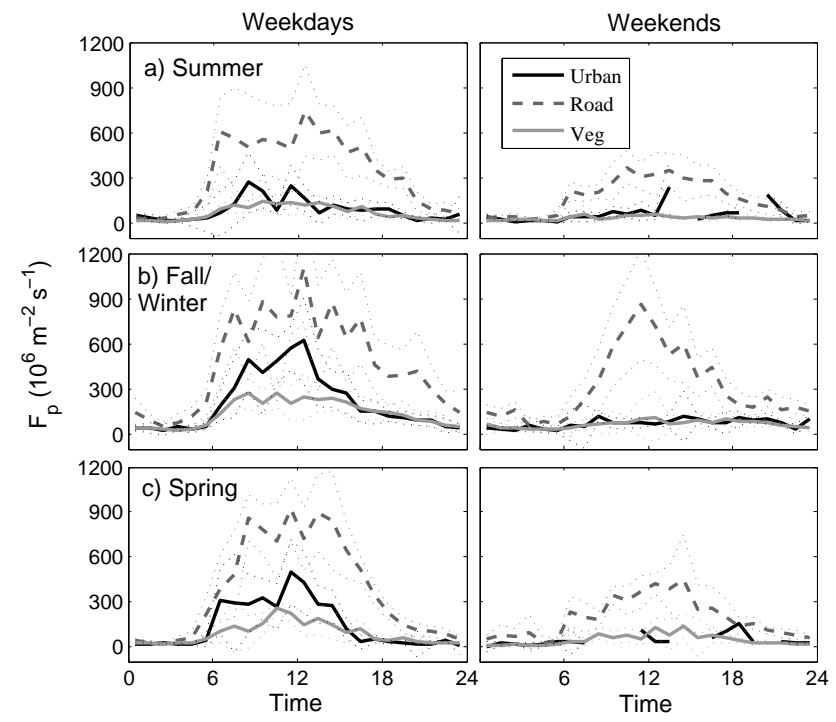

Fig. 5. The median diurnal cycle of aerosol particle number fluxes $\left(F_{p}\right)$ in different seasons and land use sectors and for weekdays and weekends separately. The dotted lines show the quartile deviations.

summer and spring. This could result from increased particle emissions from stationary combustion sources, changes in the measurement footprint, or an increased proportion of bus and heavy-duty traffic in fall/winter compared to other seasons. Particle sources dominated the deposition sink in all land use sectors, as shown in Fig. 5. However, the upward particle fluxes were systematically lower in the vegetation sector indicating weaker emissions from the footprint area. Part of these lower fluxes could also be explained by particle deposition to tree foliage. The effect of traffic activity on particle exchange was only observed on weekdays in the vegetated and urban sectors, whereas on weekends, the fluxes had no diurnal pattern.

The particle number flux statistics for the different land use types and seasons are summarised in Table 1. According to the observed similarity in number fluxes, data for day and night times, and weekends and weekdays were aggregated. In all land use sectors, the highest particle number fluxes were measured in fall/winter indicating 
Table 2. Correlation statistics of the linear regression made between aerosol particle flux $F_{p}$ (divided by $10^{6} \mathrm{~m}^{-2} \mathrm{~s}^{-1}$ ) and carbon dioxide flux $F_{c}$ (in $\mu \mathrm{mol} \mathrm{m}^{-2} \mathrm{~s}^{-1}$ ). Correlations were determined for 30 -min average flux values.

\begin{tabular}{llll}
\hline & Urb & Road & Veg \\
\hline Summer & $F_{p}=8 F_{c}+54, R^{2}=0.13$ & $F_{p}=25 F_{c}+89, R^{2}=0.43$ & $F_{p}=1 F_{c}+65, R^{2}=0.00$ \\
Fall/Winter & $F_{p}=46 F_{c}-14, R^{2}=0.34$ & $F_{p}=41 F_{c}+94, R^{2}=0.61$ & $F_{p}=42 F_{c}-21, R^{2}=0.60$ \\
Spring & $F_{p}=30 F_{c}+52, R^{2}=0.20$ & $F_{p}=36 F_{c}+15, R^{2}=0.71$ & $F_{p}=16 F_{c}+64, R^{2}=0.24$ \\
\hline
\end{tabular}
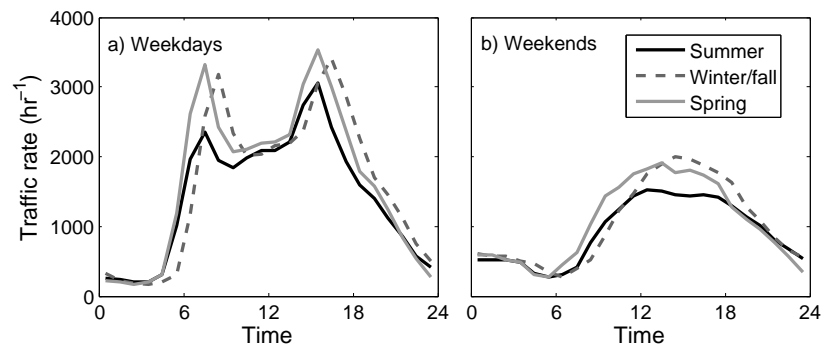

Fig. 6. Diurnal variation of traffic rate on: (a) weekdays and (b) weekends measured by the Helsinki City Planning Department at Itäväylä road (adjusted to the road next to the measurement station) between July 2007 and May 2008.

higher emissions from stationary combustion sources during the colder months. As was evident from the diurnal plots in Fig. 5, the highest fluxes were measured on weekdays, when the median fluxes ranged between 120 and $840 \times 10^{6} \mathrm{~m}^{-2} \mathrm{~s}^{-1}$. The highest fluxes were systematically measured in the road sector, and the lowest in the vegetation sector. The particle fluxes were low at night, ranging from 20 to $110 \times 10^{6} \mathrm{~m}^{-2} \mathrm{~s}^{-1}$. These observed differences between different types of land use are similar to those reported by Mårtensson et al. (2006) for Stockholm, Sweden.

The observed particle fluxes are similar to those reported in previous studies, which have reported fluxes varying between 200 and $1200 \times 10^{6} \mathrm{~m}^{-2} \mathrm{~s}^{-1}$ (Dorsey et al., 2002; Mårtensson et al., 2006; Nemitz et al., 2008). Direct comparisons are, however, difficult since the particle detection size limits vary between the different studies, and because particle fluxes are highly dependent on the measurement location, height and the intensity of traffic, which vary strongly between different studies.

\subsection{Traffic rate dependence}

The traffic flow rate showed a strong dependence on the time of day, but only a slight difference between the seasons (Fig. 6). An hourly shift in traffic rates in winter results from the change to local summer time in spring and summer. Evidently, the variation in traffic rate correlated with the diurnal pattern of particle fluxes, but the double peaked pattern observed in traffic rates due to the rush hours was not observed

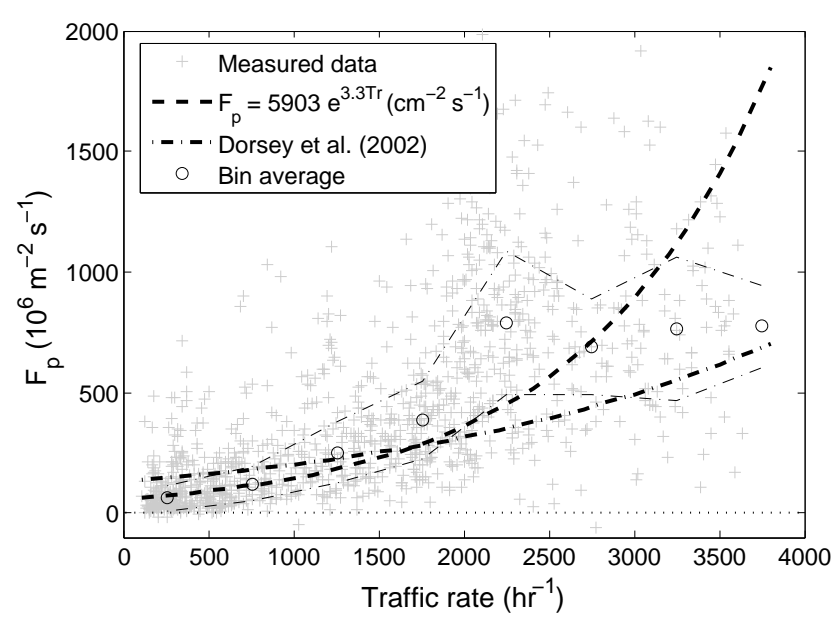

Fig. 7. Hourly correlation between particle number flux $\left(F_{p}\right)$ and traffic rate in July 2007-May 2008. The grey crosses show the hourly particle fluxes, the dashed line shows our exponential fitting $\left(F_{p}=5903 e^{3.3 T r} \mathrm{~cm}^{-2} \mathrm{~s}^{-1}\right)$, and the thick dash-dot line is the fit $\left(F_{p}=13000 e^{1.8 T r} \mathrm{~cm}^{-2} \mathrm{~s}^{-1}\right)$ obtained by Dorsey et al. (2002) for the City of Edinburgh. The circles are the median values calculated for bins of 500 vehicles $\mathrm{hr}^{-1}$, and the dash-dotted lines are the respective quartile deviations.

in particle fluxes (see also Fig. 5). This missing double peak behaviour has also been observed by Dorsey et al. (2002), Mårtensson et al. (2006) and Martin et al. (2009), and this may result from the stronger turbulent mixing around midday, or differences in footprints during different times of day. Also, a greater proportion of heavy duty vehicles (HDV) at mid-day than during rush hours could explain the mid-day flux peak, as was reported for Stockholm by Mårtensson et al. (2006).

We correlated the particle fluxes with the traffic counts in the road sector (Fig. 7), and approximated the dependence with an exponential curve similar to that in Dorsey et al. (2002), despite the distinction between linear and exponential dependence not being clear in our measurements. A non-linear relationship between traffic counts and particle emission may result from the dependence of particle emission rate on vehicle speed. During congested conditions, driving speeds commonly decrease and it has been observed 


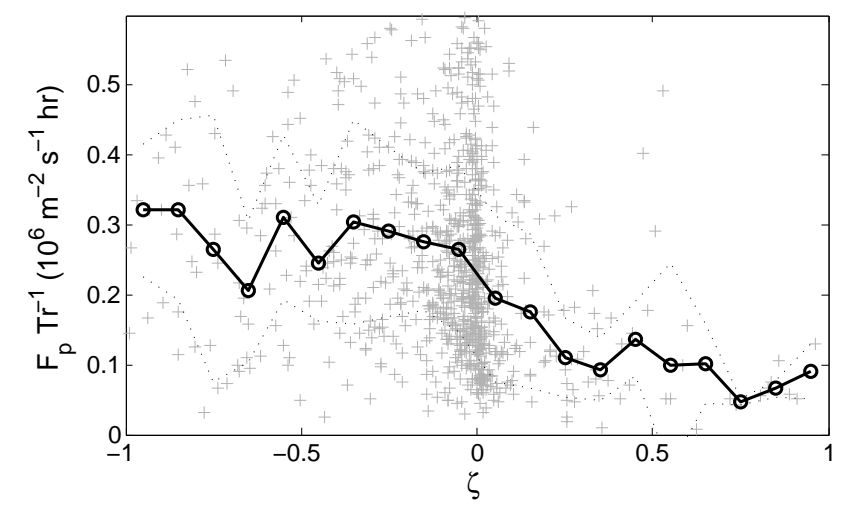

Fig. 8. The particle number fluxes normalised with traffic rate $\left(F_{p} \operatorname{Tr}^{-1}\right)$ as a function of atmospheric stability $\zeta$. Data was plotted for wind direction $40-180^{\circ}$ between July 2007 and May 2008. The circles are the median values, and the dotted lines are quartile deviations.

that below $50 \mathrm{~km} \mathrm{~h}^{-1}$ the particle emissions from road traffic increase (Ristovski et al., 2005; Morawska et al., 2007). The traffic counts do not separate heavy-duty and light-duty vehicles (HDV and LDV, respectively), increasing non-linearity between the particle emissions and traffic counts as particle emissions are an order of magnitude larger from HDV than LDV (e.g. Jones and Harrison, 2006; Ban-Weiss et al., 2009).

In addition, this non-linearity is probably affected by the dependence of fluxes on atmospheric mixing conditions as is shown in Fig. 8, where traffic normalized particle fluxes are plotted as a function of atmospheric stability in the road sector. The results indicate that unstable conditions favour stronger dependence between the traffic emissions and the measured flux.

\subsection{Correlation between the particle number and car- bon dioxide fluxes}

Correlation analysis between the particle number and carbon dioxide $\left(\mathrm{CO}_{2}\right)$ fluxes indicated similarity in their sources (Table 2). During the growing season, vegetation acts as a carbon sink during the daytime, lowering the overall EC flux. This yielded lower correlation between the two fluxes, since the particle fluxes are less affected by vegetation uptake. In the vegetation sector especially, the $\mathrm{CO}_{2}$ uptake exceeded $\mathrm{CO}_{2}$ emissions resulting in negative fluxes and vanishing correlation between the $\mathrm{CO}_{2}$ and particle number fluxes. Nemitz et al. (2008) also found a low dependence between particle and $\mathrm{CO}_{2}$ fluxes in Boulder (Colorado) in summer. In fall/winter, the fluxes showed a similar dependence in all land use sectors, i.e. the particle emission was proportional to $\mathrm{CO}_{2}$ emission. In the road sector, the correlation between the fluxes was the strongest with $R^{2}$ varying from 0.43 in summer to 0.71 during spring. The offset was always positive in the road sector indicating higher particle emissions than $\mathrm{CO}_{2}$

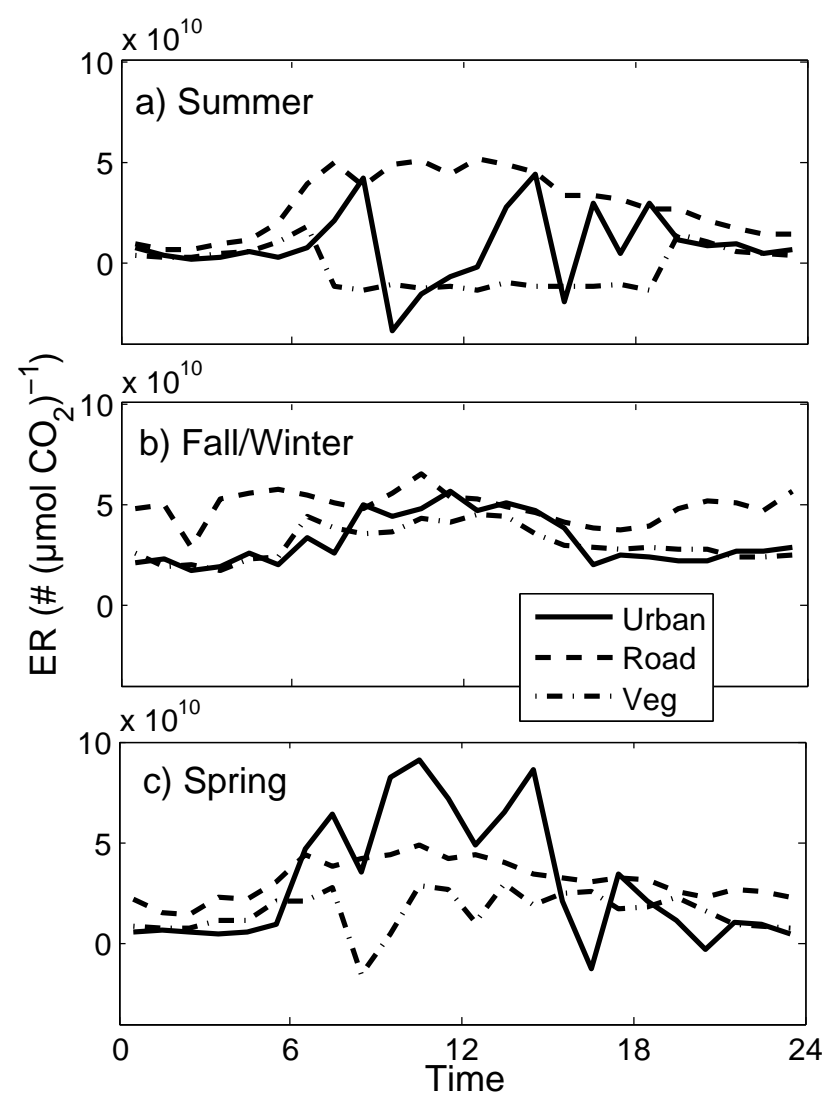

Fig. 9. The diurnal behaviour of the emission ratio (ER) of the particle number and $\mathrm{CO}_{2}$ fluxes separated by surface cover type for: (a) summer, (b) fall/winter, (c) spring.

emissions from traffic and/or from other sources. For urban and vegetation sectors, correlations were below 0.43 except in the vegetation sector in winter/fall, when $R^{2}$ reached 0.60 .

To gain more information about the relationship between the two fluxes, the diurnal behaviour of their emission ratio (ER) as a function of season and land use sectors was examined in Fig. 9. In the road sector, emissions originate mainly from traffic, and ER did not exhibit a distinguishable diurnal behaviour in fall/winter being around $5 \times 10^{10}$ \# $\left(\mu \mathrm{mol} \mathrm{CO}_{2}\right)^{-1}$. ER remained around the same level in spring and summer in the daytime, but the nocturnal ER decreased to $1 \times 10^{10} \#(\mu \mathrm{mol} \mathrm{CO})^{-1}$, probably due to the respiration of vegetation. Surprisingly, photosynthetic uptake by vegetation was not seen as a lowered daytime ER in summer in the road sector despite the vegetation cover between the road and the measurement tower. In other land use sectors the effect of vegetation was evident in summer, resulting in negative ER. Vegetation uptake was probably also responsible for the high ER (reaching $\left.8 \times 10^{10} \#(\mu \mathrm{mol} \mathrm{CO})^{-1}\right)$ in the urban sector in spring as the overall $\mathrm{CO}_{2}$ flux decreased. 


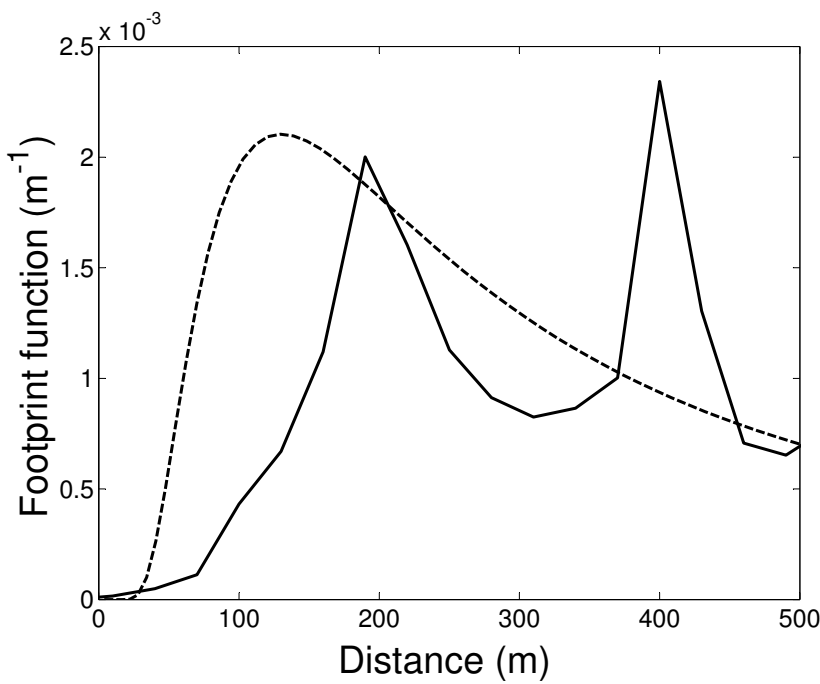

Fig. 10. Cross-wind integrated flux footprint as estimated for surface sources in the road direction with the analytical model of Horst and Weil (1994; dashed line) and the numerical model (solid line). Neutral stratification, a geostrophic wind speed of $10 \mathrm{~m} \mathrm{~s}^{-1}$ perpendicular to the road, and a measurement height of $31 \mathrm{~m}$ were assumed.

\subsection{Footprint and road source analysis}

Figure 1 shows the isolines of the calculated flux footprint function, i.e. the function relating the contribution of surface sources to the measured flux (e.g. Schmid, 2002). The flow pattern was strongly affected by buildings, and therefore the footprint function of the surface fluxes showed a complex pattern, unlike the smooth pattern characteristic of horizontally homogeneous conditions. In fact, the function had two local maxima, one close to the measurement tower and another at a distance further upwind. Model simulations also indicated that the footprint function was highly sensitive to wind direction.

Figure 10 shows the flux footprint function in a crosswind integrated form as estimated by the numerical (SCADIS model) and analytical (Horst and Weil, 1994) models. Application of the analytical model to such a complex environment can only be indicative and is used only as a comparison of how the footprint function could look like under horizontally homogeneous conditions. The footprint maximum of the numerical simulation is shifted due to topography when compared to the analytical simulation.

From the measured flux $F_{s}$ and cross-wind integrated footprint function value $F_{y}(x)$ at a distance $x$ upwind from the measurement location, the line source strength $L$ of substance $s$ (in $\mathrm{m}^{-1} \mathrm{~s}^{-1}$ ) can be estimated as $L(x)=F_{s} F_{y}(x)^{-1}$. The estimated $L$ can be used to approximate emission factors from road traffic for both particle number and $\mathrm{CO}_{2}$. The calculations were only made for atmospheric conditions representative for the footprint function $(-0.01<\zeta<0.01$, wind direction $117 \pm 25^{\circ}$ and non-geostrophic wind speed 7$9 \mathrm{~m} \mathrm{~s}^{-1}$ ) and due to these constraints only 15 suitable data points could be identified. By using these data points and an approximate footprint value $F_{y}(150 \mathrm{~m})=10^{-3} \mathrm{~m}^{-1}$ from Fig. 10, the median source strength of the road was estimated to be $0.1 \times 10^{12} \mathrm{~m}^{-1} \mathrm{~s}^{-1}$ and $0.15 \mathrm{~g} \mathrm{~m}^{-1} \mathrm{~s}^{-1}$ for particle number and $\mathrm{CO}_{2}$, respectively. If we use the measured traffic rates, previous results yield median particle and $\mathrm{CO}_{2}$ emission factors per vehicle of $(3.0 \pm 1.1) \times 10^{14} \# \mathrm{~km}^{-1}$ and (368 446$) \mathrm{g} \mathrm{km}^{-1}$, respectively. The error bounds represent standard errors. These emission factors are representative of the mixed vehicle fleet, and due to the small number of data points and uncertainties in footprint estimation, the obtained emission factors are only estimates, and should be treated with caution. However, despite our novel approach to calculating the emission factors, the values obtained correspond well with those reported in previous studies (Gramotnev et al., 2003; Ketzel et al., 2003; Ristovski et al., 2005; Jones and Harrison, 2006; Ban-Weiss et al., 2009; Birmili et al., 2009).

The advantage of estimating the emission factors from particle flux measurements using the footprint approach, or from roadside concentration measurements using dispersion modelling as in e.g. Gramotnev et al. (2003) and Birmili et al. (2009), is the generality of the result in terms of emission per vehicle per $\mathrm{km}$ of road. As discussed and summarised by Martin et al. (2008), particle flux measurements in different cities can be related directly to traffic rate and friction velocity, however, such relationships would include site specific proportionality coefficients related to location and height of the flux measurement system.

\section{Conclusions}

The temporal behaviour of aerosol particle number fluxes together with the dependencies on land use and traffic rate were studied in Helsinki, Finland between July 2007 and July 2008. The effect of mixing conditions, and correlation between particle number and $\mathrm{CO}_{2}$ fluxes and their emission ratios were also analysed.

The highest particle number fluxes were observed in winter/fall, when the medians ranged between 110 and $840 \times 10^{6} \mathrm{~m}^{-2} \mathrm{~s}^{-1}$ in daytime on weekdays. This is probably due to enhanced emissions from stationary emission sources during the colder months. However, the dependence of source footprints on boundary layer stability might also affect the observed seasonal variations. The particle fluxes had a distinct dependence on land use, with the highest values in the road sector reaching $840 \times 10^{6} \mathrm{~m}^{-2} \mathrm{~s}^{-1}$ during weekdays, and the lowest values in the vegetation sector, where the fluxes remained below $230 \times 10^{6} \mathrm{~m}^{-2} \mathrm{~s}^{-1}$. The lower fluxes in the vegetation sector are due to the low density of anthropogenic sources in the area, and particle deposition on vegetation. 
The diurnal pattern of particle number fluxes followed the measured traffic patterns closely, except the double peaked rush hour pattern was not observed in the particle number fluxes. This may result from the stronger atmospheric mixing at mid-day, as particle fluxes normalized with traffic rate were found to increase with increasing instability. The correlation between the particle number and $\mathrm{CO}_{2}$ fluxes was good, especially in the road sector, indicating similarity in their sources. However, during the growing season their correlation diminished as $\mathrm{CO}_{2}$ exchange is more strongly affected by vegetation cover than particle exchange. A numerical atmospheric boundary-layer model with sophisticated topography and land use description was used for airflow and flux footprint modeling. By using the footprint function, the median emission factors of particle number and $\mathrm{CO}_{2}$ per vehicle were estimated to be $3.0 \times 10^{14} \# \mathrm{~km}^{-1}$ and $370 \mathrm{~g} \mathrm{~km}^{-1}$, respectively.

Acknowledgements. We would like to thank the Maj and Tor Nessling foundation, TEKES (the Finnish national technology agency; Ubicasting project), and Helsinki University Environmental Research Centre (HERC) for financial support. This work was also supported by the Academy of Finland Center of Excellence program (project number 1118615) and the European Commission (projects CARBOEUROPE, IMECC, ICOS and BRIDGE). We also thank J. R. Dorsey for proof reading the paper.

Edited by: K. Hämeri

\section{References}

Ban-Weiss, G. A., Lunden, M. M., Kirchstetter, T. W., and Harley, R. A.: Measurement of black carbon and particle number emission factors from individual heavy duty vehicles, Environ. Sci. Technol., 43, 1419-1424, 2009.

Baron, P. A. and Willeke, K.: Aerosol Measurement: Principles, Techniques, and Applications, 2nd edition. John Wiley \& Sons, New York, USA, 2001.

Birmili, W., Alaviippola, B., Hinneburg, D., Knoth, O., Tuch, T., Borken-Kleefeld, J., and Schacht, A.: Dispersion of traffic related exhaust particles near the Berlin urban motorwayestimation of fleet emission factors, Atmos. Chem. Phys., 9, 2355-2374, 2009, http://www.atmos-chem-phys.net/9/2355/2009/.

Curtis, L., Rea, W., Smith-Willis, P., Fenyves, E., and Pan, Y.: Adverse health effects of outdoor air pollutants, Env. International, 32, 815-830, 2006.

Donateo, A., Contini, D., and Belosi, F.: Real time measurements of PM2.5 concentrations and vertical turbulent fluxes using an optical detector, Atmos. Environ., 40, 1346-1360, 2006.

Dorsey, J., Nemitz, E., Gallagher, M., Fowler, D., Williams, P., Bower, K., and Beswick, K.: Direct measurements and parametrisation of aerosol flux, concentration and emission velocity above a city, Atmos. Environ., 36, 791-800, 2002.

Glasius, M., Ketzel, M., Wåhlin, P., Jensen, B., Mønster, J., Berkowicz, R., and Palmgren, F.: Impact of wood combustion on particle levels in a residential area in Denmark, Atmos Environ., 40, 7115-7124, 2006.
Gramotnev, G., Gramotneva, G., Brown, R., Ristovski, Z., Hitchins, J., and Morawska, L.: Determination of average emission factors for vehicles on a busy road, Atmos. Environ., 37, 465-474, 2003.

Grimmond, C. S. B. and Oke, T.: Aerodynamic properties of urban areas derived from analysis of surface form, J. Appl. Meteorol., 38, 1262-1292, 1999.

Foken, T. and Wichura, B.: Tools for quality assessment of surfacebased flux measurements, Agric. For. Meteorol., 78, 83-105, 1996.

Hering, S. V., Stolzenburg, M. R., Quant, F. R., Oberreit, D. R., and Keady, P. B.: A laminar-flow, water-based condensation particle counter (WCPC), Aerosol Sci. Technol., 39, 659-672, 2005.

Horst, T. W. and Weil, J. C.: How far is far enough? The fetch requirements for micrometeorological measurement of surface fluxes, J. Atmos. Ocean. Technol., 11, 1018-1025, 1994.

Horst T. W.: A simple formula for attenuation of eddy fluxes measured with first-order-response scalar sensors, Bound.-Lay. Meteorol., 82, 219-233, 1997.

Intergovernmental Panel on Climate Change: Climate Change 2007: The Physical Science Basis, Contribution of Working group I to the Fourth Assessment Report of the Intergovernmental Panel on Climate Change, edited by: Solomon, S., Qin, D., and Manning, M., Cambridge University Press, 2007.

Jones, A. M. and Harrison, R. M.: Estimation of the emission factors of particle number and mass fractions from traffic at a site where mean vehicle speeds vary over short distances, Atmos. Environ., 40, 7125-7137, 2006.

Järvi, L., Hannuniemi, H., Hussein, T., Junninen, H., Aalto, P. P., Hillamo, R., Mäkelä, T., Keronen, P. Siivola, E., Vesala, T., and Kulmala, M.: The urban measurement station SMEAR III: Continuous monitoring of air pollution and surface-atmosphere interactions in Helsinki, Finland, Boreal Env. Res., 14 (Suppl. A), 86-109, 2009.

Kaimal, J. C., Wyngaard, J. C., Izumi, Y. and Coté, O. R.: Spectral characteristics of surface-layer turbulence, Q. J. Roy. Meteor. Soc., 98, 563-589, 1972.

Keeler, G., Morishita, M., and Young, L.-H.: Characterization of complex mixtures in urban atmospheres for inhalation exposure studies, Exp. Toxic. Path., 57, 19-29, 2005.

Ketzel, M., Wåhlin, P., Berkowicz, R., and Palmgren, F.: Particle and trace gas emission factors under urban driving conditions in Copenhagen based on street and roof-level observations, Atmos. Environ., 37, 2735-2749, 2003.

Kumar, P., Fennell, P., and Britter, R.: Measurements of particles in the 5-1000 nm range close to road level in an urban street canyon, Sci. Total Environ., 390, 437-447, 2008.

Lilleberg, I. and Hellman, T.: Liikenten kehitys Helsingissä vuonna 2008 (in Finnish), Publications by Helsinki City Planning Department, 2009:1, 2009.

Longley, I. D., Gallagher, M. W., Dorsey, J. R., and Flynn, M.: A case-study of fine particle concentrations and fluxes measured in a busy street canyon in Manchester, UK, Atmos. Environ., 38, 3595-3603, 2004a.

Longley, I. D., Gallagher, M. W., Dorsey, J. R., Flynn, M., Bower, K. N., and Allan, J. D.: Street canyon aerosol pollutant transport measurements, Sci. Total Environ., 334-335, 327-336, 2004b.

Mammarella, I., Launiainen, S., Grönholm, T., Keronen, P., Pumpanen, J., Rannik, Ü., and Vesala, T.: Relative humidity effect on the high-frequency attenuation of water vapour flux measured by 
a closed-path eddy covariance system, J. Atmos. Ocean. Tech., 26, 1856-1866, 2009.

Martin, C. L., Longley, I. D., Dorsey, J. R., Thomas, M. R., Gallagher, M. W., and Nemitz, E.: Ultrafine particle fluxes above four major European cities, Atmos. Environ., 43, 4714-4721, doi:10.1016/j.atmosenv.2008.10.009, 2008.

McMillen, R. T.: An eddy correlation technique with extended applicability to non-simple terrain, Bound.-Lay. Meteorol., 43, 231-245, 1988.

Moore, C. J.: Frequency response corrections for eddy correlation systems, Bound.-Lay. Meteorol., 37, 17-36, 1986.

Morawska, L., Ristovski, Z. D., Johnson, G. R., Jayaratne, E. M., and Mengersen, K.: Novel method for on-road emission factor measurements using a plume capture trailer, Environ. Sci. Technol. 41, 574-579, 2007.

Mårtensson, E., Nilsson, E., Buzorius, G., and Johansson C.: Eddy covariance measurements and parameterisation of traffic related particle emissions in an urban environment, Atmos. Chem. Phys., 6, 769-785, 2006, http://www.atmos-chem-phys.net/6/769/2006/.

Nemitz, E., Fowler, D., Dorsey, J. R., Theobald, M. R., McDonald, A. D., Bower, K. N., Beswick, K. M., Williams, P. I., and Gallagher, M. W.: Direct measurement of size-segregated particle fluxes above a city, J. Aerosol Sci., 31 (Suppl. 1), 116-117, 2000.

Nemitz, E., Jimenez, J. L., Huffman, J. A., Ulbrich, I. M., Canagaratna, M. R., Worsnop, D. R., and Guenther, A. B.: An eddycovariance system for the measurement of surface/atmosphere exchange fluxes of submicron aerosol chemical species - First application above an urban area, Aerosol Sci. Technol., 42, 636657,2008

Niemi, J., Väkevä, O., Kousa, A., Weckström, M., Julkunen, A., Myllynen, M., and Koskentalo, T.: Air Quality in the Helsinki Metropolitan Area in 2007 (in Finnish), YTV Helsinki Metropolitan Area Council, 8/2008, 2008.

Pakkanen, T., Loukkola, K. Korhonen, C. H., Aurela, M., Mäkelä, T., Hillamo, R., Aarnio, P., Koskentalo, T., Kousa, A., and Maenhaut W.: Sources and chemical composition of atmospheric fine and coarse particles in the Helsinki area, Atmos. Environ., 35, 5381-5391, 2001.

Palmgren, F., Berkowicz, R., Ziv, A., and Hertel, O.: Actual car fleet emissions estimated from urban air quality measurements and street pollution models, Sci. Total Environ. , 235, 101-109, 1999.

Pryor, S. C., Larsen, S. E., Sørensen, L. L., Barthelmie, R. J., Grönholm, T., Kulmala, M., Launiainen, S., Rannik, Ü., and Vesala, T.: Particle fluxes over forests: Analyses of flux methods and functional dependencies, J. Geophys Res., 112, D07205, doi:10.1029/2006JD008066, 2007.

Pryor, S. C., Gallagher, M., Sievering, H., Larsen, E., Barthelmie, R. J., Birsan, F., Nemitz, E., Rinne, J., Kulmala, M., Grönholm, T., Taipale, R., and Vesala, T.: A review of measurement and modelling results of particle atmosphere-surface exchange, Tellus B, 60, 42-75, 2008.
Rannik, Ü. and Vesala, T.: Autoregressive filtering versus linear detrending in estimation of fluxes by the eddy covariance method, Bound.-Lay. Meteorol., 91, 259-280, 1999.

Rannik, Ü., Keronen, P. Hari, P., and Vesala, T.: Estimation of forest-atmosphere $\mathrm{CO}_{2}$ exchange by eddy covariance and profile techniques, Agr. For. Meteorol., 126, 141-155, 2004.

Ristovski, Z. D., Jayaratne, E. R., Morawska, L., Ayoko, G. A., and Lim, M.: Particle and carbon dioxide emissions from passenger vehicles operating on unleaded petrol and LPG fuel, Sci. Total Environ., 345, 93-98, 2005.

Schmid, H. P.: Footprint modeling for vegetation atmosphere exchange studies: a review and perspective. Agr. For. Meteorol., 113, 159-183, 2002.

Schmidt, A. and Klemm, O.: Direct determination of highly sizeresolved turbulent particle fluxes with the disjunct eddy covariance method and a 12-stage electrical low pressure impactor, Atmos. Chem. Phys., 8, 7405-7417, 2008, http://www.atmos-chem-phys.net/8/7405/2008/.

Sogachev, A., Menzhulin, G., Heimann, M., and Lloyd, J.: A simple three-dimensional canopy - planetary boundary layer simulation model for scalar concentrations and fluxes, Tellus B, 54(5), 784819, 2002.

Sogachev, A. and Lloyd, J.: Using a one-and-a-half order closure model of the atmospheric boundary layer for surface flux footprint estimation, Bound.-Lay. Meteorol., 112, 467-502, 2004.

Sogachev, A., Rannik, Ü., and Vesala, T.: On flux footprints over the complex terrain covered by a heterogeneous forest, Agric. For. Meteorol., 127, 143-158, 2004.

Sogachev, A. and Panferov, O.: Modification of two-equation models to account for plant drag, Bound.-Lay. Meteorol., 121, 229266, 2006.

Sogachev, A.: A Note on Two-Equation Closure Modelling of Canopy Flow, Bound.-Lay. Meteorol., 130, 423-435, doi:10.1007/s10546-008-9346-2, 2009.

Thomas, S. and Morawska, L.: Size-selected particles in an urban atmosphere of Brisbane, Australia, Atmos. Environ., 36, 42774288, 2002.

Vesala, T., Järvi, L., Launiainen, S., Sogachev, A., Rannik, Ü., Mammarella, I., Siivola, E., Keronen, P., Rinne, J., Riikonen, A., and Nikinmaa, E.: Surface-atmosphere interactions over complex urban terrain in Helsinki, Finland, Tellus B, 60, 188-199, 2008.

Young, L.-H. and Keeler, G.: Summertime ultrafine particles in urban and industrial air: aitken and nucleation mode particle event, Aerosol Air Qual. Res., 7, 379-402, 2007. 